\title{
Avoidance Responses of Minke Whales to 1-4 kHz Naval Sonar
}

Petter H Kvadsheim ${ }^{1 *}$, Stacy DeRuiter ${ }^{2}$, Lise D Sivle ${ }^{3}$, Jeremy Goldbogen ${ }^{4}$, Rune RolandHansen $^{5}$, Patrick JO Miller ${ }^{6}$, Frans-Peter A Lam ${ }^{7}$, John Calambokidis ${ }^{8}$, Ari Friedlaender ${ }^{9}, 10$, Fleur Visser ${ }^{11,12}$, Peter L Tyack ${ }^{6}$, Lars Kleivane ${ }^{1}$ and Brandon Southall ${ }^{10,13}$

${ }^{1}$ Norwegian Defence Research Establishment (FFI), NO-3191 Horten, Norway

${ }^{2}$ Calvin College, Department of Mathematics and Statistics, Grand Rapids, MI 49546-4301, USA

${ }^{3}$ Institute of Marine Research (IMR), NO-5817 Bergen, Norway

${ }^{4}$ Hopkins Marine Station, Stanford University, Pacific Grove, CA USA

${ }^{5}$ University of Oslo, Department of Biosciences, NO-0316 Oslo, Norway

${ }^{6}$ Sea Mammal Research Unit, University of St Andrews, St Andrews, KY16 9LB, UK

${ }^{7}$ Netherlands Organisation for Applied Scientific Research (TNO), The Hague, The Netherlands

${ }^{8}$ Cascadia Research Collective, Olympia, WA 98501, USA

${ }^{9}$ Department of Fisheries and Wildlife, Marine Mammal Institute, Hatfield Marine Science Center, Oregon State University, 2030 Marine Science Drive, Newport, OR 97365, USA.

${ }^{10}$ Southall Environmental Associates Inc., Aptos, CA 95003, USA

${ }^{11}$ Kelp Marine Research (KMR), 1624 CJ, Hoorn, The Netherlands

${ }^{12}$ Behavioural Biology, Institute of Biology, Leiden University, 2333 BE, Leiden, The Netherlands

${ }^{13}$ Long Marine Laboratory, University of California, Santa Cruz, Institute of Marine Sciences, Santa Cruz, CA 95060, USA

*Corresponding author

Petter H Kvadsheim

phk@,ffi.no

Norwegian Defence Research Establishment (FFI)

NO-3191 Horten, Norway

Key Words: Behavioural response, naval sonar, minke whale, Balaenoptera acutorostrata,

North Pacific, North Atlantic 


\begin{abstract}
Minke whales are difficult to study and little information exists regarding their responses to anthropogenic sound. This study pools data from behavioural response studies off California and Norway. Data are derived from four tagged animals, of which one from each location was exposed to naval sonar signals. Statistical analyses were conducted using Mahalanobis distance to compare overall changes in parameters summarising dive behaviour, avoidance behaviour, and potential energetic costs of disturbance. Our quantitative analysis showed that both animals initiated avoidance behaviour, but responses were not associated with unusual dive behaviour. In one exposed animal the avoidance of the sonar source included a 5-fold increase in horizontal speed away from the source, implying a significant increase in metabolic rate. Despite the different environmental settings and exposure contexts, clear changes in behavior were observed providing the first insights into the nature of responses to human noise for this wide-ranging species.
\end{abstract}

\title{
Highlights
}

- Data pooled across two projects to increase sample size.

- Quantitative analysis shows that minke whales avoid naval sonar at low levels.

- Minke whales are likely to be affected by sonar across relatively large distances.

- Results are consistent with observations from a real world scenario.

- First insight into the responses of this common species to anthropogenic sound. 


\section{Introduction}

Naval anti-submarine warfare sonars, typically operating in the 1-10 kHz frequency band, have been associated with atypical mass strandings of cetaceans (D'Amico et al. 2009). These events have mostly involved beaked whales (family Ziphiidae), but during the 2000 Bahamas stranding event, two minke whales (Balaenoptera acutorostrata) were also found stranded (Balcomb \& Claridge 2001). In addition to their potential role in infrequent but lethal stranding events, sublethal behavioural responses to anthropogenic sound that affect foraging or reproductive behaviours of a large number of whales may lead to longer-term cumulative effects on the vital rates of whale populations. Behavioural response studies (BRS) using controlled exposure experiments (CEE) initially tended to focus on beaked whales, given their disproportionate frequency in strandings. These and other studies on toothed whales (suborder Odontoceti), have shown that behavioural effects of sonar can range from subtle effects such as short term changes in vocal behaviour (Alves et al. 2014) and dive patterns (Sivle et al. 2012, Stimpert et al. 2014) to more severe responses such as habitat avoidance (Tyack et al. 2011, DeRuiter et al. 2013, Miller et al. 2015, Sivle et al. 2015) typically also associated with cessation of feeding (Tyack et al. 2011, Miller et al. 2012, DeRuiter et al. 2013, Sivle et al. 2015, Isojunno et al. 2016) and even separation from dependent offspring (Miller et al. 2012).

Similar to behavioral responses observed in odontocetes, CEEs with baleen whales (suborder Mysticeti), specifically humpback whales and blue whales (Balaenoptera musculus) have documented responses including changes in vocal behaviour (Miller et al. 2000, Fristrup et al. 2003), changes in dive pattern, avoidance, and cessation of feeding (Maybaum 1993, Goldbogen et al. 2013, Sivle et al 2015, Sivle et al. 2016, Friedlaender et al. 2016). Cetacean species have thus generally been shown to exhibit responses to naval sonar. However, inter- and intra-individual, species and population responses are highly variable, and it has been proposed that contextual factors such as prey availability (Friedlaender et al. 2016), behavioural and 
motivational state of the animal, the nature and novelty of the sound, and the sound source spatial configuration relative to the receiving animal are important factors that explain some of this variation (Ellison et al. 2012, Southall et al. 2016).

Minke whales are among the most abundant and ubiquitous baleen whales worldwide. Given their size, speed, and agility, minke whales are known to be difficult to track visually and to approach closely to tag (Kvadsheim et al. 2015). Consequently, despite interest in their potential responsiveness to sonar and their likely common exposure to military sonar and other human sounds, little direct information exists on their sensitivity to sound. In a recent study, the number of acoustic detections of minke whales was found to drop significantly during naval sonar activity off Hawaii (Martin et al., 2015), suggesting a silencing response and/or behavioural avoidance of sonar. As in other baleen whales which are bulk filter-feeders with large body size that require high densities of patchily-distributed prey, minke whales have relatively high energetic demands that require very high feeding rates (Friedlaender et al. 2014). Within rorquals, body sizes range from minke whales at the smaller end to blue whales as the largest species, which strongly affects feeding frequencies and energetic demands (Goldbogen et al. 2012). The evidence that behavioral responses of baleen whales to noise predominately relate to changes in foraging behavior, highlights the importance of analyzing the potential energetic consequences of responses across species of different body size and energetic demands.

Using a structured qualitative method of identifying and evaluating the severity of behavioural responses, Sivle et al. (2015) found that a minke whale tagged in the north Atlantic showed strong avoidance responses. The objective of this study is to combine datasets from two different BRS projects on minke whales using a quantitative analysis to assess whether, how, and at what levels minke whales may respond to sonar. 


\section{Methods}

\section{Research animals and data collection}

The Southern California Behavioral Response Study (SOCAL-BRS) has been conducted in the central eastern Pacific Ocean off the coast of southern California (Southall et al. 2012), whereas the Sea Mammals and Sonar Safety (3S) research effort (Kvadsheim et al. 2015) has worked off the coast of northern Norway and Spitsbergen in the northeast Atlantic Ocean. Data were collected from four minke whales (Balaenoptera acutorostrata), two tagged off the coast of southern California by the SOCAL BRS project (ba13_265 and ba14_211) (Southall et al. 2012), and two tagged in Norwegian waters by the 3S BRS project (ba10_148 and bal1_180) (Kvadsheim et al. 2015) (Table S1, supplementary material). Two of the animals were subjects in Controlled Exposure Experiments (CEE) (bal1_180 (3S-CEE), ba14_211 (SOCAL-CEE), one from each location, and for two animals only baseline data were collected (ba10_148 (3Sbaseline), ba13_265(SOCAL-baseline) (Table S1).

\section{Experimental procedures}

Details of the methodology are described in Southall et al. (2012) for the SOCAL dataset and in Kvadsheim et al. (2015) for the 3S dataset. Archival tags were attached to the animals by suction cups attached to the skin or (in the case of $3 S-C E E$ ) an invasive $50 \mathrm{~mm}$ barb penetrating into the blubber. Three different tags were used as indicated in Table S1: DTAGs (Johnson and Tyack 2003) sampling 3D magnetic field, 3D acceleration, and pressure (depth) at $50 \mathrm{~Hz}$, as well as stereo hydrophones sampling sound at $64 \mathrm{kHz}$; and MK9 tags (Wildlife Computers, Redmond, WA, USA) and time-depth recorder (TDR) tags (Star-Oddi, Gardabaer, Iceland) sampling only pressure (depth) at $1 \mathrm{~Hz}$ and $0.25 \mathrm{~Hz}$, respectively. In addition, all tags had a VHF transmitter which allowed tracking of the focal whale at the surface, and recovery of the tag when it released from the whale after 3-19 h. Focal follows of the tagged whales were only done for 3S-baseline 
and $3 S$-CEE. After 12 and $6 \mathrm{hrs}$ of collection of data on baseline behaviour for $3 S-C E E$ and SOCAL-CEE, respectively, the sonar exposures were conducted. The protocols used for the exposures differed somewhat between $3 S-C E E$ and SOCAL-CEE, but the idea behind both was to escalate the dose of sound exposure on the tagged whale, to enable us to determine received level thresholds of response onset. During the exposure of $3 S$-CEE, the source ship started at a distance of $9 \mathrm{~km}$ from the animal, and approached the tagged whale at a speed of 8-9 knots (4.0$4.5 \mathrm{~m} \cdot \mathrm{s}^{-1}$ ) towing a sonar source at a depth of $65 \mathrm{~m}$ on an estimated intercept course. Sonar transmissions were initiated using a 10 min ramp-up of the source level (ISO 2017) from $152 \mathrm{~dB}$ to a maximum level of $214 \mathrm{~dB}$ re $1 \mu \mathrm{Pa} \cdot \mathrm{m}$, and continuing for another $60 \mathrm{~min}$ at the maximum level. The transmitted signals consisted of 1.3-2.0 kHz hyperbolic frequency modulated upsweep signals (Ainslie 2010) with a duration of $1 \mathrm{~s}$, transmitted every $20 \mathrm{~s}$ (5\% duty cycle). Two hours before the sonar exposure subject $3 S-C E E$ was first exposed to a 40 min no-sonar control experiment, where the animal was approached by the source ship as if it was a sonar exposure but no sonar signals were transmitted. After the exposures, post-exposure data were collected for another $5 \mathrm{~h}$, before the tag released and was recovered. During the exposure of subject $S O C A L$ $C E E$, the source ship was stationary in a starting position estimated to be $1-2 \mathrm{~km}$ from the animal. The source was lowered to a depth of $10 \mathrm{~m}$ and sonar transmissions were initiated by a 7 min ramp-up of the source level from $160 \mathrm{~dB}$ to a maximum level of $210 \mathrm{~dB}$ re $1 \mu \mathrm{Pa} \cdot \mathrm{m}$, and continuing for another $23 \mathrm{~min}$ at the maximum level. However, the tag released from the whale $21 \mathrm{~min}$ into the exposure, and the data record was thereby interrupted. The transmitted signals consisted of a 3.5-3.6 kHz linear frequency modulated (Ainslie 2010) up-sweep (0.5 s), then a $3.75 \mathrm{kHz}$ tone $(0.5 \mathrm{~s})$, a $0.1 \mathrm{~s}$ delay and then finally a $4.05 \mathrm{kHz}$ tone $(0.5 \mathrm{~s})$ with a total duration of $1.6 \mathrm{~s}$, transmitted every $25 \mathrm{~s}(6 \%$ duty cycle). These waveforms and duty cycles were designed to be similar to some of the signals used in operational naval sonar systems, although 
the maximum transmitted source level was lower than most of these tactical systems in operation.

\section{Data analysis}

CEE Received levels:

For SOCAL-CEE the maximum sound pressure level (SPLmax abbreviated henceforth "SPL") of each sonar ping was quantified as the maximum RMS sound pressure level received by the sensors in the tag in any $200 \mathrm{~ms}$ time window in the $1 / 3$ octave band between 3.3 and $4.2 \mathrm{kHz}$ (centred at $3.7 \mathrm{kHz}$ ) (Southall et al. 2012). The cumulative sound exposure level (SEL, ISO 2017) of all pings thus far during the exposure was also computed, in the same frequency band. SEL is calculated by integrating over the duration of the pulses, including only periods where signal to noise ratio exceeded $6 \mathrm{~dB}$. The tag on the $3 S-C E E$ did not contain any acoustic sensors, and received levels therefore had to be estimated from propagation loss (ISO 2017) calculations using an incoherent ray trace model in two dimensions (horizontal distance and depth). Inputs to the model included the transmission characteristics of the source and sound speed profiles, which were measured immediately following exposure (Kvadsheim et al. 2015). Sound pressure levels received by $3 S-C E E$ were then calculated as the source level minus the propagation loss for individual pings, and are based on RMS values between $1.3-2.0 \mathrm{kHz}$ averaged across the entire 1 s pulse. Received level estimates for $3 S-C E E$ were validated against levels measured on a calibrated hydrophone towed by a small boat tracking within a few hundred meters of the whale (Kvadsheim et al. 2015). To make SPL numbers directly comparable between SOCAL-CEE and 3S-CEE, we calculated the difference between SPL using $200 \mathrm{~ms}$ averaging time and $1 \mathrm{~s}$ averaging time for all pulses received on the array. The average difference of $2.1 \mathrm{~dB}$ was then added to the estimated received level of $3 S-C E E$ to get a value comparable to the SPL value of SOCAL-CEE. The average difference between the SPL values measured on the hydrophone array 
and the estimated SPL values on the array using modelling gives an indication of the accuracy of the modelling and was found to be $3 \mathrm{~dB}$. SEL values for $3 S$-CEE were calculated by integrating across the entire $1 \mathrm{~s}$ pulse in the $1.3-2.0 \mathrm{kHz}$ band.

Distance to the source:

Distance to source is another relevant metric of exposure intensity. For $3 S-C E E$ this was estimated from the GPS position of the source ship and the position of the whale at the time of each transmission based on the focal follow track, with linear interpolation between observed positions. For SOCAL-CEE there was no focal follow track, but a relative distance from the source to the animal was calculated based on time-of-flight analysis, where distance equals the time difference between transmission and arrival of the signal on the DTAG multiplied by the speed of sound through the water. The tag detached from the whale 9 min before the end of exposure, and was recovered $87 \mathrm{~min}$ later in a position that was $1.2 \mathrm{~km}$ from the position of the source. Based on this recovery position and the calculated relative distance, we estimate that SOCAL-CEE was approximately $1 \mathrm{~km}$ from the source at the start of the exposure with an estimated error of $\pm 1 \mathrm{~km}$ due to drift of the tag at the surface between detachment from the whale and recovery.

Dive parameters:

For all depth records, a dive was defined as a vertical excursion to a depth greater than $3 \mathrm{~m}$, and a number of dive parameters of interest were calculated for each dive: maximum depth (m), dive duration (min), descent rate (mean descent rate $(\mathrm{m} / \mathrm{s})$ from start of descent until $85 \%$ of the maximum dive depth for that dive), ascent rate (mean ascent rate from last time depth exceeded $85 \%$ of the maximum for that dive to surfacing), bottom duration (time (min) from end of descent to start of ascent), surface interval (time (min) from surfacing until start of next dive), number of breaths (number of surfacings in the post dive surface interval). To account for possible effects of the tagging, the first dive after tagging was excluded. 
Time series parameters:

For the two exposure experiments, the following time series data were extracted in addition to the dive data: 1) Animal speed (flow noise for $S O C A L-C E E$ as a proxy for speed through the water (Miller et al. 2004), and horizontal speed for 3S-CEE based on the focal follow track). 2) Variability of heading (circular variance of heading based on the magnetic sensors on the DTAG computed in a one-minute sliding window for SOCAL-CEE; and radial distance between three surfacing positions (distance between first and last) divided by the cumulative distance between all three surfacing positions, based on the focal follow track, for 3S-CEE). 3) Respiration rate (number of surfacings per $\mathrm{h}$ based on the dive records, averaged over a 10 min sliding window). 4) Variability of respiration rate (standard deviation of respiration rate, computed in a 10-minute sliding window). 5) Overall dynamic body acceleration (ODBA, as an indication of metabolic rate (Wilson et al. 2006), based on acceleration sensors on the DTAG and therefore only estimated for SOCAL-CEE). All data streams were sampled at $25 \mathrm{~Hz}$ for SOCAL-CEE, and at $0.25 \mathrm{~Hz}$ for $3 S$-CEE.

\section{Statistical analysis}

Two types of analysis were conducted: a dive-by-dive analysis using the dive parameters specified above from all four data records, including the two baseline records, and a time series change-point analysis of the data from the two exposure experiments to identify the onset of behavioural responses to sonar. In both of these analyses we have used a metric based on Mahalanobis distance to summarize several parameters and quantify how much behaviour differs from a baseline period. This Mahalanobis distance can be considered to be a measure of response intensity (DeRuiter et al 2013), and the method has been used in several similar studies on other species (DeRuiter et al. 2013, Miller et al. 2014, Antunes et al. 2014, Miller et al. 2015). 
Dive-by-dive analysis:

All dives were clustered into short-shallow, long-deep and intermediate dives by k-means clustering based on depth and duration. The number of clusters was selected using silhouette analysis (Rousseeuw, 1987). Using all the dive parameters above as input, we then calculated the Mahalanobis distance between each dive and the average value for baseline dives of the same cluster type. To analyse whether the sonar exposure might have led to changes in dive behaviour, we then fitted a model describing Mahalanobis distance as a function of received level, sourceto-whale range, and time since the last sonar exposure (DeRuiter et al. 2013) to the data from each sonar-exposed whale (because precise data on source-to-whale range were not available for SOCAL-CEE, the range covariate was excluded from the full model for that whale). We then compared the full models to models without received level, range, and time-decay covariates, using Akaike's information criterion (AIC) to select the best model for each sonar-exposed whale.

Time series analysis:

The 5 time-series parameters of the two data records of animals exposed to sonar were reduced to two using metrics based on Mahalanobis distance. One metric combined parameters related to the movement of the animal (animal speed and variability of heading), and was used to test the hypothesis that animals were avoiding the sonar, i.e. change in speed or heading to increase separation distance to the source. Previous studies have shown that speed and/or directedness of the animal typically change during avoidance responses (e.g. Miller et al. 2012, Sivle et al. 2015). The other metric combined parameters related to the energetics of the animals (animal speed and respiration rate (Blix and Folkow 1999), variability of respiration rate (Roos et al. 2016) and ODBA (Wilson et al. 2006)), and was used to test the hypothesis that there was an energetic cost of responding. For each of these two metrics we calculated the Mahalanobis distance between the average data values for the baseline period and the average data values 
within a 5-minute comparison window. This comparison window slid forward over the dataset with 4.5 minutes of overlap, providing an output distance every $30 \mathrm{~s}$. Distance values were reported at the centre time of each window. We used a simple resampling method to look for a change-point in the resulting Mahalanobis distance time-series. We sampled (with replacement) 100,000 random contiguous blocks of data from within the control period. These random blocks were of the same duration as the sonar exposure period. The time-order of the data in the random block was not altered or randomised, in order to preserve the autocorrelation structure of the data. We used the set of maximum values from the random blocks (one from each of the 100,000 randomisations) to estimate an empirical distribution function for the expected maximum distance during a baseline period of the same duration as the exposure. We set a threshold for change-point detection (change from normal or baseline behaviour) at the 95th percentile of the expected distances from the randomisations. 


\section{Results}

More than 30 hours of data were recorded from four different animals in the two different locations (Table S1). During sonar exposure, the 3S-CEE whale was exposed to SPLs ranging from $85-160 \mathrm{~dB}$ re $1 \mu \mathrm{Pa}$, SEL from $83-177 \mathrm{~dB}$ re $\mu \mathrm{Pa}^{2} \cdot \mathrm{s}$ and source to whale range from 3-9 $\mathrm{km}$, whereas SOCAL-CEE whale was exposed to SPLs ranging from 97-146 dB re $1 \mu \mathrm{Pa}$, SEL from 89-151 $\mathrm{dB}$ re $\mu \mathrm{Pa}^{2} \cdot \mathrm{s}$ and source to whale range from about $1-3 \mathrm{~km}$.

Dive-by-dive analysis:

The 4 baseline records show that minke whales rarely dive deeper than $120 \mathrm{~m}$ (Figure 1). Dives were clustered into long-deep dives, intermediate dives and short-shallow dives (Figure 1), with $12 \%, 26 \%$ and $61 \%$ of all dives in each of these clusters, respectively. In the baseline period the distribution of dives was $14 \%$ long-deep dives, $29 \%$ intermediate dives and $57 \%$ short shallow dives, whereas during the sonar exposure the distribution of dives was $12 \%$ long-deep dives, $23 \%$ intermediate dives and $65 \%$ short-shallow dives. The dive-by-dive Mahalanobis distance metric combines all dive parameters into one metric of dive behaviour and compares each dive to the average value of the baseline dives within the same cluster (Figure S1). For the models describing dive-by-dive Mahalanobis distance as a function of received level and source-towhale range, the model with intercept only (no effect of range to source or received level, and no time-decay) was the best model for both the exposed animals according to AIC, with AIC at least 2 units below the next competing model. Thus, the dive behaviour during sonar exposure seems to have been within the normal behavioural repertoire of the two exposed animals.

Time series analysis:

Visual inspection of the time series of behavioural parameters of the two exposed animals (Figure 2), show that $3 S$-CEE increased horizontal speed from around $1 \mathrm{~ms}^{-1}$ at the start of the sonar exposure to a maximum speed of $5 \mathrm{~ms}^{-1}$ during the exposure. This is by far the highest speed within the $19 \mathrm{~h}$ record. At the same time as the speed increased, the animal's movement 
also became very directional, and respiration rate increased, but not beyond levels seen during the baseline period. Near the end of the 70 min exposure, the speed and respiration rates levelled off at high levels, but the time between respirations became almost constant (very low standard deviation of respiration rate). Speed, respiration rate and variability of respiration timing seemed to return to pre-exposure levels within $30 \mathrm{~min}$ after the exposure.

For SOCAL-CEE the most striking change in the behavioural parameters during the exposure was that the animal, which had been doing regular deep dives (>80 $\mathrm{m}$ ) and moving in an erratic pattern for hours before the exposure, became very directional in its movement pattern during the sonar exposure, but maintaining a diving pattern and swim speed similar to that before the exposure (Figure 2).

For both animals, the Mahalanobis distance analysis to test the avoidance hypothesis detected breakpoints in the data during the exposures at 12:35:34 h:min:s into the data record or 19:34 min:s into the exposure for 3S-CEE, and at 06:07:00 h:min:s into the data record or 08:10 min:sec into the exposure for SOCAL-CEE (Figure 3). The detected avoidance responses happened at a received $\mathrm{SPL}=156 \mathrm{~dB}$ re $1 \mu \mathrm{Pa}$ (maximum received level prior to response), $\mathrm{SEL}=166 \mathrm{~dB}$ re $\mu \mathrm{Pa}^{2} \cdot \mathrm{s}$ and estimated range to the source of $6.0 \mathrm{~km}$ for $3 S-C E E$, and $\mathrm{SPL}=146$ $\mathrm{dB}$ re $1 \mu \mathrm{Pa}, \mathrm{SEL}=149 \mathrm{~dB}$ re $\mu \mathrm{Pa}^{2} \cdot \mathrm{s}$ and estimated range to the source of $1-2 \mathrm{~km}$ for SOCAL-CEE (Figure 4). The Mahalanobis distance analysis to test the energetic cost hypothesis detected a breakpoint for 3S-CEE at 12:48:34 h:min:s into the record or 32:34 min:s into the exposure, but no change-point was detected for SOCAL-CEE (Figure 3). The energetic response in $3 S$-CEE happened at $\mathrm{SPL}=158 \mathrm{~dB}$ re $1 \mu \mathrm{Pa}, \mathrm{SEL}=170 \mathrm{~dB} \mathrm{re} \mu \mathrm{Pa}^{2} \cdot \mathrm{s}$ and estimated range to the source of $4.6 \mathrm{~km}$ (Figure 4). A change-point for avoidance parameters but not for energetic parameters was also detected during the no-sonar control exposure in 3S-CEE (Figure 3). The response intensity was much lower than during the sonar exposure, but this still indicates some avoidance of the approaching ship also when it was not transmitting sonar signals. 


\section{Discussion}

Data were successfully collected from four minke whales, two from the eastern North Pacific and two from the eastern North Atlantic oceans (Table S1). Two of these animals, one from each location, were exposed to naval sonar signals during CEEs (Southall et al. 2012, Kvadsheim et al. 2015). However, there were some differences in tag types, experimental sound sources, and data sampling procedures, and therefore the datasets have somewhat different qualities. These differences, as well as differences in the movement of the sources and other aspects of sonar exposure, complicate pooling of data. However, given the elusive behaviour of minke whales, approaching them close enough for tagging is challenging (Kvadsheim et al. 2015), thus sampling a large number of animals is difficult. Despite significant effort to increase the sample size, we did not manage to tag more than 2 in either site. Pooling data from different studies using consistent analytical approaches on this important and interesting species, is therefore particularly rewarding. We have used quantitative analyses to investigate how and at what levels minke whales respond to $1-4 \mathrm{kHz}$ naval sonar. Our results show that both a minke whale in the central eastern Pacific and a minke whale in the northeast Atlantic responded by avoiding the sonar source (Figure 3), and in the Atlantic whale there was also an apparent energetic cost of responding. However, the outcome of the dive-by-dive analysis implies that dive behaviour during exposure was within the normal range observed for these animals.

The exposed individual SOCAL-CEE responded at lower levels $(\mathrm{SPL}=146 \mathrm{~dB})$ than the individual exposed in 3S (3S-CEE, SPL=156 dB) (Figure 4), but the magnitude of the response of $3 S-C E E$ was clearly higher than in SOCAL-CEE. Contextual variables, including exposure variables such as relative movement of the source, and many individual parameters that are not known for these subjects (e.g. exposure history), are likely to affect responsiveness (e.g. Ellison et al. 2012). Recent studies suggest that in beaked whales, the probability of response to sonar may be influenced by the distance from the source to the whale (DeRuiter et al. 2013, Moretti et 
al. 2014). In the exposure of SOCAL-CEE, the animal was on the order of 1-2 $\mathrm{km}$ from the source at the start of the exposure, compared to $9 \mathrm{~km}$ range at the start of the exposure in $3 S$ $C E E$. The proximity of the source could explain why the exposure level at which an avoidance response was observed to occur for SOCAL-CEE was somewhat lower than in $3 S-C E E$. On the other hand, in 3S-CEE the source ship approached the animal quickly, whereas in SOCAL-CEE the source ship was stationary during transmissions. SOCAL-CEE could thereby easily escape by directional movements away from the source, without increasing swim speed, wheras in $3 S-C E E$ the directional movement away from the source was accompanied by a significant increase in swim speed from $1 \mathrm{~m} \cdot \mathrm{s}^{-1}$ to $5 \mathrm{~m} \cdot \mathrm{s}^{-1}$ (Figure 2). The increase in swim speed implies that there was at least a threefold increase in metabolic rate associated with the avoidance (Blix \& Folkow 1995). $3 S-C E E$ swam at a speed that exceeded the estimated optimal swim speed of $3.25 \mathrm{~m} \cdot \mathrm{s}^{-1}$ for minke whales (Blix and Folkow 1995), which may indicate a strong motivation to escape. Consistent with these observations, our time series analysis identified a significant energetic cost of responding in $3 S-C E E$.

Naval sonar has been shown to interrupt feeding in blue whales (Goldbogen et al. 2013) and humpback whales (Sivle et al. 2016). Lost feeding opportunities may have a bigger impact on energy balance than increased expenditure of energy due to locomotion (Goldbogen et al. 2013, Isojunno et al. 2016). In SOCAL-CEE there was no indication of lunge feeding prior to exposure, and for $3 S-C E E$ we do not know if the animal stopped feeding, because analysis of lunging would have required an acoustic sensor on the tag. Thus, these initial results do not allow us to fully evaluate the energetic consequences of responses in minke whales.

Another factor which might have influenced differences in responses is differences in the frequency bands of the sonar signals used in the two exposure experiments $(1.3-2.0 \mathrm{kHz}$ for $3 S$ $C E E$, and $3.5-4.05 \mathrm{kHz}$ for $S O C A L-C E E)$. However, minke whales are expected to have sensitive hearing across these frequency bands (Tubelli et al. 2012), and studies on other species 
have found that response thresholds do not vary with sonar frequency within the $1-8 \mathrm{kHz}$ band tested (Miller et al 2014, Antunes et al. 2014), even where hearing sensitivity varies considerably across this range. Natural variation in sensitivity between individuals or a systematic difference in sensitivity between two populations are also possible, but based on this very limited dataset, we cannot conclude that there are any population differences. However, if such differences exist it might be explained by the fact that minke whales are still harvested in the Northeast Atlantic whereas that is not the case in the Northeastern Pacific. The context of on-going whaling nearby might explain the avoidance of the approaching ship in 3S-CEE (Figure 3), and might also contribute to the much stronger response to sonar seen in $3 S$-CEE compared to SOCAL-CEE.

The key response parameters driving the Mahalanobis distance change-points during sonar exposure appear to be the directed movement away from the source in SOCAL-CEE (Figure 2), and the combination of directedness and increase in swim speed in $3 S$-CEE. In the latter case there was also an increase in respiration rate associated with the increase in swim speed, but despite the fact that swim speed during the avoidance was much higher than anything seen during the baseline period, respiration rate never increased beyond the normal range. However, a recent study showed that during high-speed swimming, killer whales optimize respiration intervals to maximize oxygen uptake per respiration and minimize surface drag (Roos et al. 2016). This means that the relationship between respiration rate and metabolic rate is complex (Roos et al. 2016). In 3S-CEE, the time between breaths becomes almost constant (variability of respiration rate dropped) during the high-speed escape (Figure 2), which suggests that minke whales might have a similar mechanism as killer whales to optimize swimming and maximize oxygen uptake.

Both animals responded to naval sonar exposure by leaving the area. Since the experimental exposures were short, this displacement is not expected to have a significant impact on the experimental subjects. $3 S-C E E$ even returned to the pre-exposure area shortly after end of 
exposure. However, real naval operations could last for days, and this could potentially lead to more serious exclusion from important habitats. Our observations of avoidance responses at relatively low levels during experimental sonar exposure of minke whales are actually consistent with the significant reductions in minke whales vocalizing observed over a $3800 \mathrm{~km}^{2}$ area during an actual naval sonar operation off Hawaii during the breeding period (Martin et al. 2015). Depending on source level used and propoagation condition, the avoidance response threshold observed in our study (146-156 dB SPL re $1 \mu \mathrm{Pa}$ ) predicts avoidance over this big an area. If we compare the avoidance response threshold for minke whales as determined in this study to other species, minke whales seem to have a sensitivity to sonar which is similar to killer whales (Miller et al. 2014) and blue whales (Goldbogen et al. 2013), they are more sensitive than pilot whales (Antunes et al. 2014) and humpback whales (Sivle et al. 2015), but less sensitive than beaked whales (Tyack et al. 2011, DeRuiter et al. 2013, Miller et al. 2015). 


\section{Conclusion}

We have shown in two separate studies that minke whales show avoidance to naval sonar. Our sample size is low (only two exposed whales), but the consistency of the results from our controlled exposure experiments with observations from a real world scenario imply that minke whales are likely to be affected by naval sonar activity across relatively large distances. Despite the different environmental settings and exposure contexts for our subjects, clear changes in behaviour were observed, providing the first insights into the nature of responses to human noise for this wide-ranging species. 


\section{Acknowledgments}

The SOCAL BRS project, the 3S BRS project and the MOCHA project contributed to this study. The SOCAL project was funded by the US Navy Chief of Naval Operations Environmental Readiness Division and US Office of Naval Research. The 3S project was funded by the Norwegian Ministry of Defence, the US Office of Naval Research, the Netherlands Ministry of Defence and DGA French Ministry of Defence. The MOCHA project was funded by the US Office of Naval Research. Tyack received funding from the MASTS pooling initiative (The Marine Alliance for Science and Technology for Scotland) and their support is gratefully acknowledged. MASTS is funded by the Scottish Funding Council (grant reference HR09011) and contributing institutions. The SOCAL-experiments were conducted under permit number 14534 issued by the US National Marine Fisheries Service, and the 3S-experiments were conducted under permit number S-2011/38782 issued by the Norwegian Animal Research Authority. Michael Ainslie (TNO), Paul Wensveen (SMRU) and Nina Nordlund (FFI) are acknowledged for their helpful advice on the presentation of acoustic data used in this paper.

\section{Disclosure Statement}

All authors have seen and approved the final version of the manuscript being submitted. We warrant that the article is the authors' original work, hasn't received prior publication and isn't under consideration for publication elsewhere. There's no conflict of interest including financial or personal interest or belief that could affect the objectivity of any of the authors. The funding sources for this study are listed in the acknowledgments. Sponsors did not contribute to or influence study design, data analysis and interpretation nor in the preparation of this manuscript. Sponsors did contribute to data collection at sea. 


\section{Literature Cited}

Ainslie MA (2010). Principles of Sonar Performance Modeling, Springer, 2010

Alves A, Antunes R, Bird A, Tyack, P, Miller PJO, Lam FPA, Kvadsheim PH (2014). Vocal matching of naval sonar signals by long-finned pilot whales (Globicephala melas). Marine Mammal Sci 30:1248-1257. DOI: 10.1111/mms.12099.

Antunes R, Kvadsheim PH, Lam FPA, Tyack PL, Thomas L, Wensveen PJ, Miller PJO. (2014).

High response thresholds for avoidance of sonar by free-ranging long-finned pilot whales (Globicephala melas). Mar. Poll. Bull. 83: 165-180. DOI: 10.1016/j.marpolbul.2014.03.056

Balcomb KC \& Claridge DE (2001). A mass stranding of cetaceans caused by naval sonar in the Bahamas. Bahamas Journal of Science 5:2-12.

Blix AS \& Folkow LP (1999). Daily energy expenditure in free living minke whales. Acta Physiol. Scand. 153:61-66

D’Amico A, Gisiner RC, Ketten DR, Hammock JA, Johnson C, Tyack PL, \& Mead J (2009).

Beaked whale strandings and naval exercises. Aquatic Mammals 34(4):452-472.

doi:http://dx.doi.org/10.1578/AM

DeRuiter SL, Southall BL, Calambokidis J, Zimmer WMX, Sadykova D, Falcone EA, Friedlaender JEJ, Moretti D, Schorr GS, Thomas L, Tyack PL (2013). First direct measurements of behavioural responses by Cuvier's beaked whales to mid-frequency active sonar. Biology Letters 9:20130223. doi:10.1098/rsbl.2013.0223

Ellison WT, Southall BL, Clark CW, Frankell AS (2012). A new context-based approach to assess marine mammal behavioral responses to anthropogenic sounds. Cons Biol. 26(1):21-28. 
Friedlaender AS, Goldbogen JA, Nowacek DP, Read AJ, Johnston D, Gales N (2014). Feeding rates and under-ice foraging strategies of the smallest lunge filter feeder, the Antarctic minke whale (Balaenoptera bonaerensis). Journal of Experimental Biology 217(16):2851-2854. doi:10.1242/jeb.106682

Friedlaender AS, Hazen EL, Goldbogen JA, Stimpert AK, Calambokidis J, Southall BL (2016). Prey-mediated behavioral responses of feeding blue whales in controlled sound exposure experiments. Ecological Applications 26(4): 1075-1085. DOI: 10.1002/15-0783.

Fristrup KM, Hatch LT, Clark CW (2003). Variation in humpback whale (Megaptera novaeangliae) song length in relation to low-frequency sound broadcasts. Journal of the Acoustical Society of America 113(6):3411-3424. doi:10.1121/1.157363

Goldbogen JA, Calambokidis J, Croll DA, McKenna MF, Oleson E, Potvin J, Pyenson ND, Schorr G, Shadwick RE, Tershy BR (2012). Scaling of lunge-feeding performance in rorqual whales: mass-specific energy expenditure increases with body size and progressively limits diving capacity. Functional Ecology 26(1):216-226. doi:10.1111/j.1365-2435.2011.01905.x

Goldbogen JA, Southall BL, DeRuiter SL, Calambokidis J, Friedlaender AS, Hazen EL, Falcone EA, Schorr GS, Douglas A, Moretti DJ, Kyburg C, McKenna MF, Tyack PL (2013). Blue whales respond to simulated mid-frequency military sonar. Proceedings of the Royal Society B-Biological Sciences 280:20130657. doi:10.1098/rspb.2013.0657

ISO (2017). ISO 18405 - Underwater Acoustics - Terminology, International Organization for Standardization, Geneva, 2017

Isojunno S, Curé C, Kvadsheim PH, Lam FPA, Tyack PL, Wensveen PJ, Miller PJO (2016). Sperm whales reduce foraging effort during exposure to 1-2 kHz sonar and killer whale sounds. Ecological Applications 21(1):77-93 
Johnson MP \& Tyack PL (2003). A digital acoustic recording tag for measuring the response of wild marine mammals to sound. IEEE Journal of Oceanic Engineering 28:3-12. doi:http://dx.doi.org/10.1109/Joe

Kvadsheim PH, Lam FP, Miller P, Sivle LD, Wensveen P, Roos M, Tyack P, Kleivane L, Visser F, Curé C, van Ijsselmuide S, Isojunno S, von Benda-Beckmann S, Nordlund N, Dekeling R (2015). The 3S2 experiments - Studying the behavioural effects of naval sonar on northern bottlenose whales, humpback whales and minke whales. FFI-rapport 2015/01001 (http://rapporter.ffi.no/rapporter/2015/01001.pdf).

Martin SW, Martin CR, Matsuyama BM, Henderson EE (2015). Minke whales (Balaenoptera acutorostrata) respond to navy training. Journal of Acoustical Society of America 137(5):25332541. http://dx.doi.org/10.1121/1.4919319

Maybaum HL (1993). Responses of humpback whales to sonar sounds. Journal of Acoustical Society of America 94:1848. doi:http://dx.doi.org/10.1121/1.407710

Miller PJO, Biassoni N, Samuels A, Tyack PL (2000). Whale songs lengthen in response to sonar. Nature 405(6789):903-903. doi:10.1038/35016148

Miller PJO, Johnson MP, Tyack PL, Terray EA (2004). Swimming gaits, passive drag and buoyancy of diving sperm whales (Physeter catadon). J. Exp. Biol. 207:1953-1967.

Miller PJO, Kvadsheim PH, Lam FPA, Wensveen PJ, Antunes R, Alves AC, Visser F, Kleivane L, Tyack PL, Sivle LD (2012). The severity of behavioral changes observed during experimental exposures of killer (Orcinus orca), long-finned pilot (Globicephala melas), and sperm whales (Physeter macrocephalus) to naval sonar. Aquatic Mammals 38:362-401. 
Miller PJO, Antunes R, Wensveen P, Samarra FIP, Alves AC, Tyack P, Kvadsheim PH, Kleivane L, Lam FP, Ainslie M, Thomas L (2014). Dose-response relationships for the onset of avoidance of sonar by free-ranging killer whales. J. Acoust. Soc Am.135:975-993.

Miller PJO, Kvadsheim PH, Lam FPA, Tyack PL, Curé C, DeRuiter SL, Kleivane L, Sivle L, van IJsselmuide SP, Visser F, Wensveen PJ, von Benda-Beckmann AM, Martin López L, Narazaki T, Hooker SK (2015). First indications that northern bottlenose whales are sensitive to behavioural disturbance from anthropogenic noise. $R$. Soc. open sci. 2:140484.

http://dx.doi.org/10.1098/rsos.140484

Moretti D, Thomas L, Marques T, Harwood J, Dilley A, Neales R, Shaffer J, McCarthy E, New L, Jarvis S, Morrissey R (2014) A risk function for behavioural disruption of Blainville's beaked whales (Mesoplodon densirostris) from mid-frequency active sonar. PLoS ONE 9(1):e85064 doi:10.1371/journal.pone.0085064

Roos MH, Wu GM, Miller PJO (2016). The significance of respiration timing in the energetics estimates of free-ranging killer whales (Orcinus orca). J. Exp. Biol. 219:2066-2077 doi:10.1242/jeb.137513

Rousseeuw PJ (1987). Silhouettes: A graphical aid to the interpretation and validation of cluster analysis. Journal of Computational and Applied Mathematics 20:53-65. doi:10.1016/03770427(87)90125-7.

Sivle LD, Kvadsheim PH, Fahlman A, Lam FP, Tyack P, Miller P (2012). Changes in dive behavior during sonar exposure in killer whales, pilot whales and sperm whales. Frontiers in Aquat. Physiol. 3:400. doi:10.3389/fphys.2012.00400 
Sivle L, Kvadsheim PH, Curé C, Isojunno S, Wensveen PJ, Lam FPA, Visser F, Kleivane L, Tyack PL, Harris C, Miller PJO (2015). Severity of expert-identified behavioural responses of humpback whale, minke whale and northern bottlenose whale to naval sonar. Aquatic Mammals 41(4):469-502 DOI 10.1578/AM.41.4.2015.469

Sivle LD, Wensveen PJ, Kvadsheim PH, Lam FPA, Visser F, Curé C, Harris CM, Tyack PL, Miller PJO (2016). Naval sonar disrupts foraging in humpback whales. Marine Ecology Progress Series 562:211-220. doi:10.3354/meps11969

Southall BL, Moretti D, Abraham B, Calambokidis J, DeRuiter SL, Tyack PL (2012). Marine mammal behavioral response studies in Southern California: advances in technology and experimental methods. Marine Technology Society Journal 46(4):48-59.

Southall BL, Nowacek DP, Miller PJO, Tyack PL (2016). Experimental field studies to measure behavioral responses of cetaceans to sonar. Endangered Species Research 31: 293-315. doi:10.3354/esr00764

Stimpert AK, DeRuiter S, Southall B, Moretti D, Falcone E, Goldbogen J, Friedlaender AS, Schorr G, Calambokidis J (2014). Acoustic and foraging behavior of a tagged Baird's beaked whale exposed to simulated sonar. Scientific Reports 4:7031. DOI 10.1038.srep/07031

Tubelli AA, Zosuls A, Ketten DR, Yamato M, Mountain DC (2012). A prediction of the minke whale (Balaenoptera acutorostrata) middle-ear transfer function. Journal of the Acoustical Society of America 132(5):3263-3272. doi:10.1121/1.4756950

Tyack PL, Zimmer WMX, Moretti D, Southall BL, Claridge DE, Durban JW, Clark CW, D’Amico A, DiMarzio N, Jarvis S, McCarthy E, Morrissey R, Ward J, Boyd IL (2011). Beaked whales respond to simulated and actual navy sonar. PLoS One 6(3):e17009.

doi:10.1371/journal.pone.0017009 
Wilson RP, White CR, Quintana F, Halsey LG, Liebsch N, Martin GR, Butler PJ (2006). Moving towards acceleration for estimates of activity-specific metabolic rate in free-living animals: the case of the cormorant. J. Anim. Ecol. 75:1081-1090. doi:10.1111/j.1365-2656.2006.01127.x 


\section{Figure Legends}

Figure 1: Dive profiles (top panels) and dive parameters (lower panels) by dive type (long-deep dives (left), intermediate dives (middle) and short-shallow dives (right)) for all four animals. Note the different $\mathrm{X}$ - and $\mathrm{Y}$-axis scales on the upper panels. In the top panels, dives without exposure are plotted in grey, dives during controlled exposures to sonar in red, and postexposure dives by the exposed whale in blue. Lower panels contain box-plots of dive parameters. Here control observations include dives by unexposed animals, as well as pre-exposure dives by the exposed whales. To facilitate showing many variables on a single plot, all values were scaled before plotting by dividing by the maximum of the absolute value of all control observations. Black boxes span 25th-75th percentiles, black horizontal lines mark medians, error bars extend 1.5 interquartile ranges beyond the boxes, and + symbols indicate more extreme values. Dive parameters from exposed dives and the post-exposure dives are plotted individually. Symbol and color-coding matches the top panels.

Figure 2. Time-series data plots for the two animals exposed to sonar, 3S-CEE (left) and SOCALCEE (right). From the top, plots show dive depth, speed/flow-noise, directedness/headingvariability, respiration rate, variability of respiration rate and ODBA (only measured in SOCAL$C E E$ ). See text for details of parameters. The no-sonar-control exposure period is indicated in green and the sonar exposure periods in red.

Figure 3: Time series Mahalanobis distance for avoidance parameters (top panels) and energetic parameters (lower panels) for the two animals exposed to sonar, $3 S-C E E$ (left) and SOCAL-CEE (right). The no-sonar-control exposure period is indicated in green and the sonar exposure period in red. The dashed horizontal lines indicate the response threshold. 
Figure 4. Transmitted source level in $\mathrm{dB}$ re $1 \mu \mathrm{Pa} \cdot \mathrm{m}(\bullet)$, measured or modelled received RMS sound pressure level in $\mathrm{dB}$ re $1 \mu \mathrm{Pa}(\mathrm{o})$, accumulated sound exposure level in $\mathrm{dB}$ re $1 \mu \mathrm{Pa}^{2} \cdot \mathrm{s}(-)$ and range from source to animal in $\mathrm{m}(--)$ as a function of time in minutes during sonar exposure experiment $3 S-C E E$ (top panel) and SOCAL-CEE (lower panel). The vertical lines indicate times of response onset based on Mahalanobis distance analysis, with light grey lines for avoidance and a dark line for energetics. In the top panel range is given as absolute range based on tracks of the source ship and the focal animal, whereas in the lower panel range is given relative to the range at the start of the exposure based on time of flight analysis (range at time 0 (first ping) is defined to be 0 ). Note that in experiment $3 S$-CEE the source was approaching the whale at 8-9 knots speed, while in SOCAL-CEE the source was stationary. 
Figures
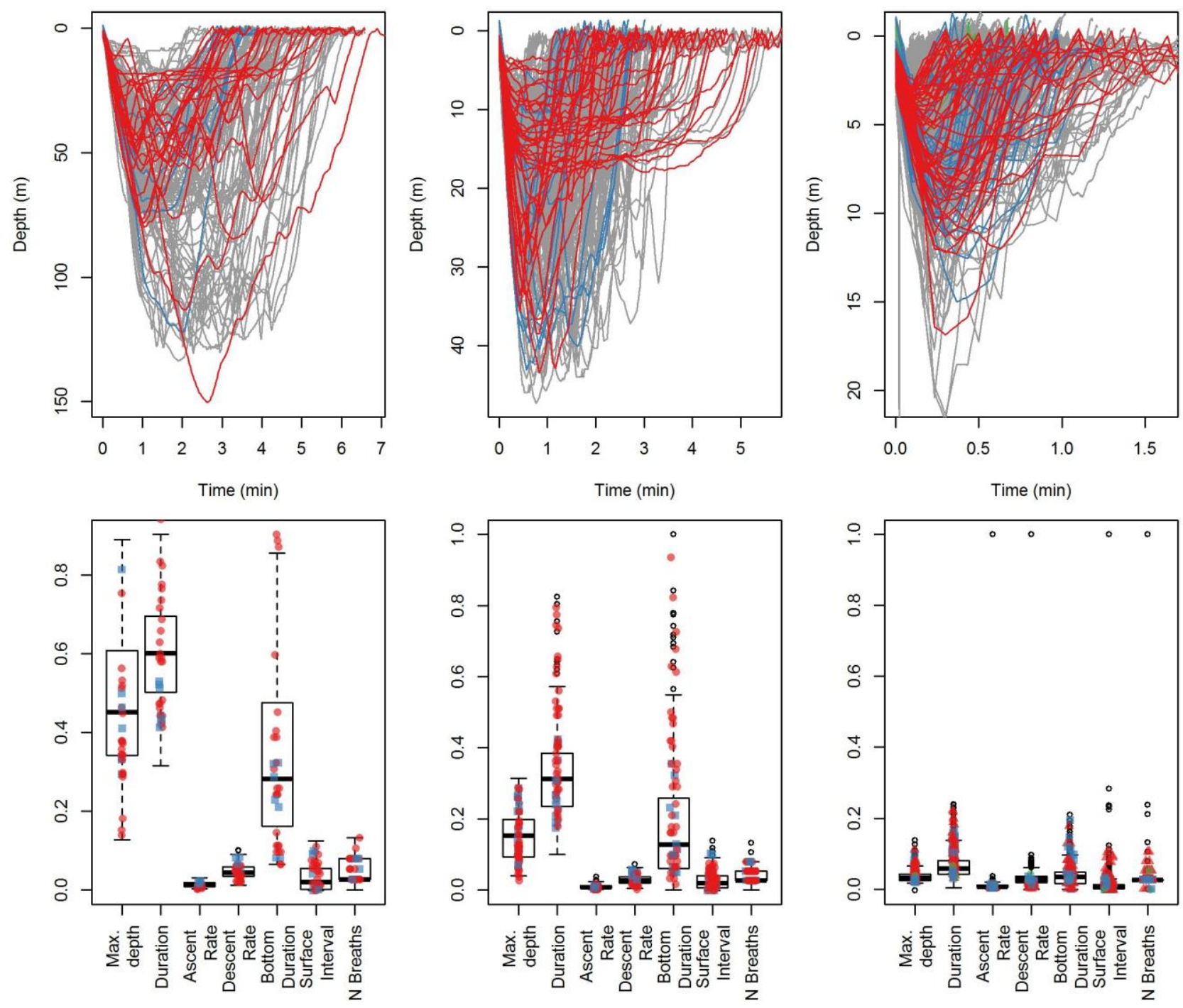

Figure 1: 

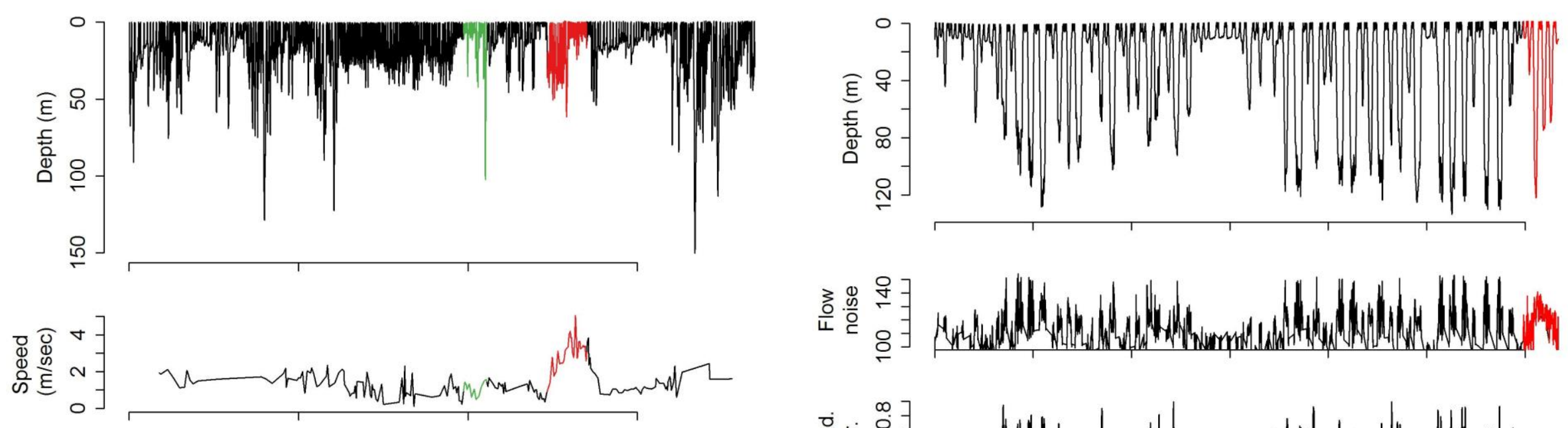

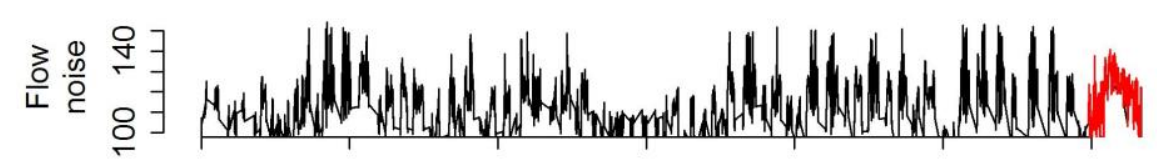

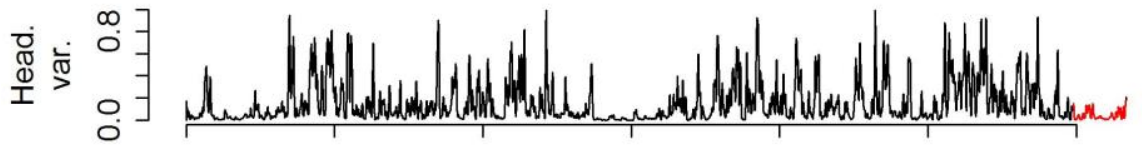

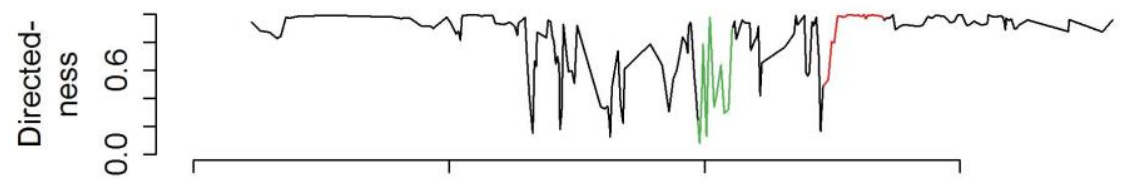

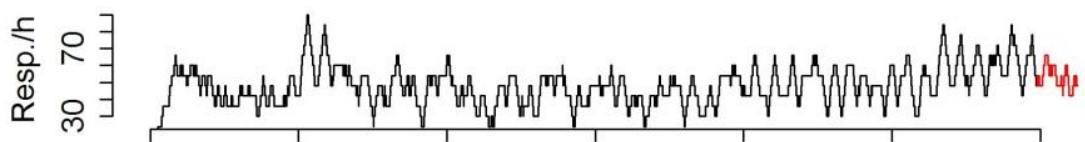

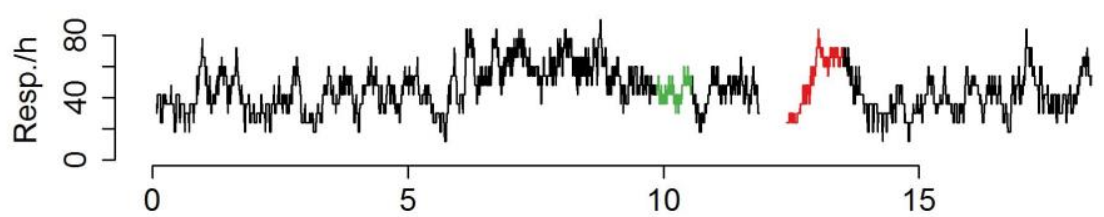

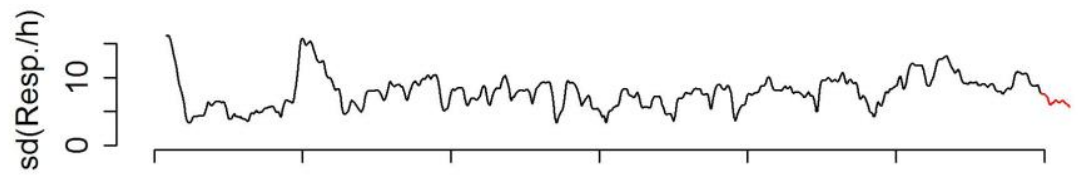

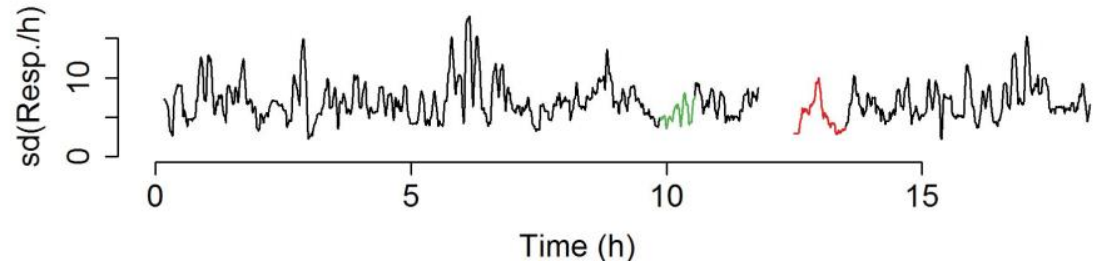

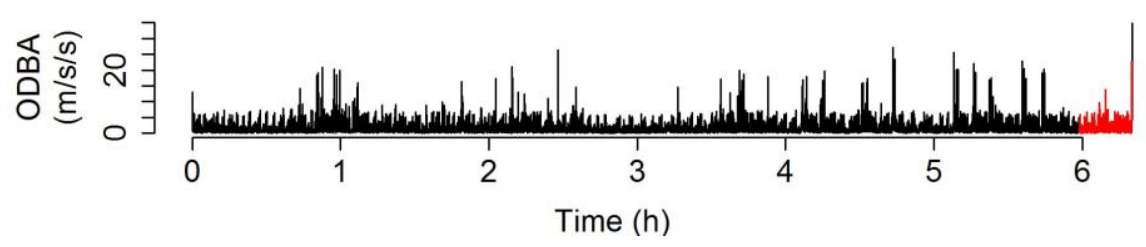

Figure 2. 

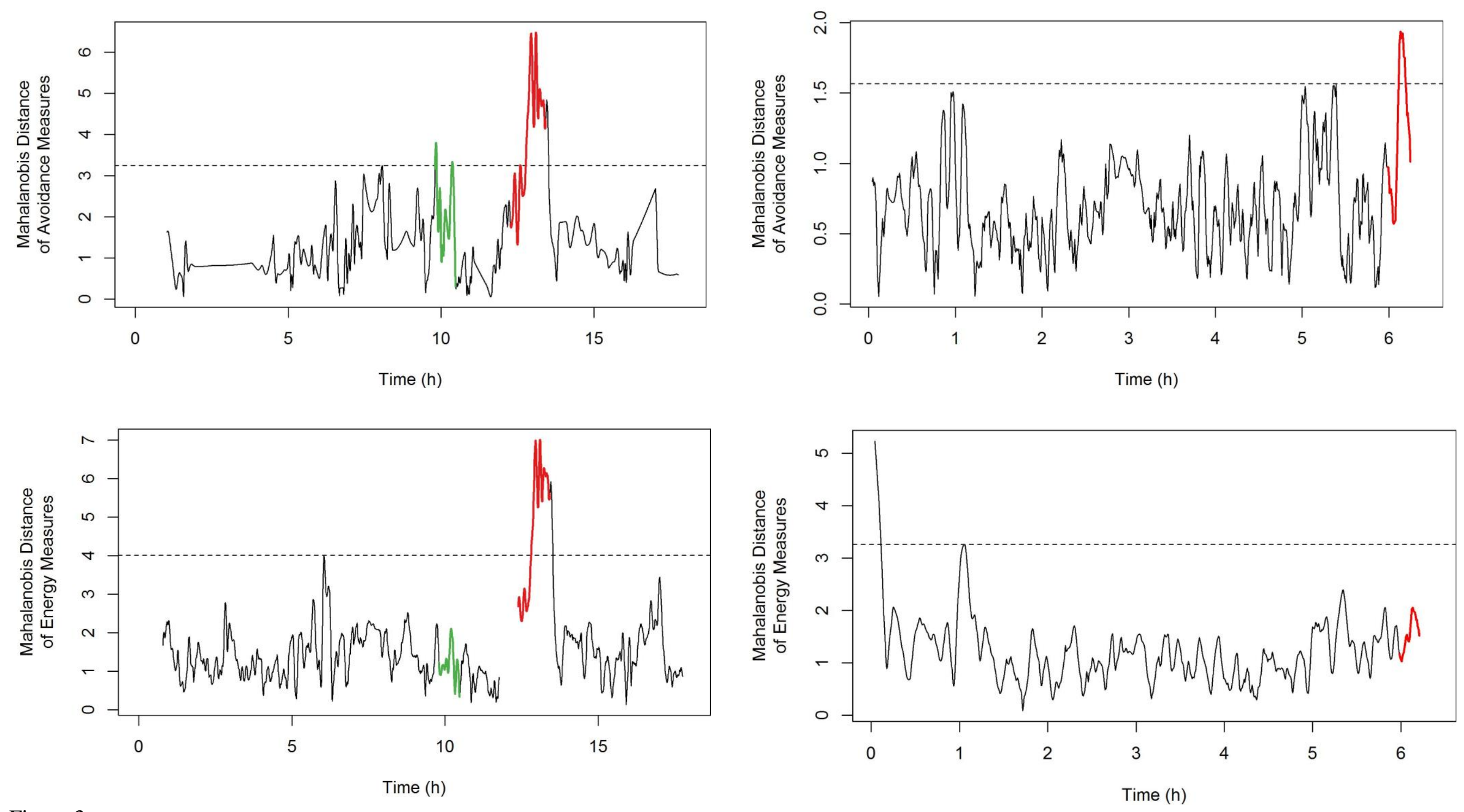

Figure 3 

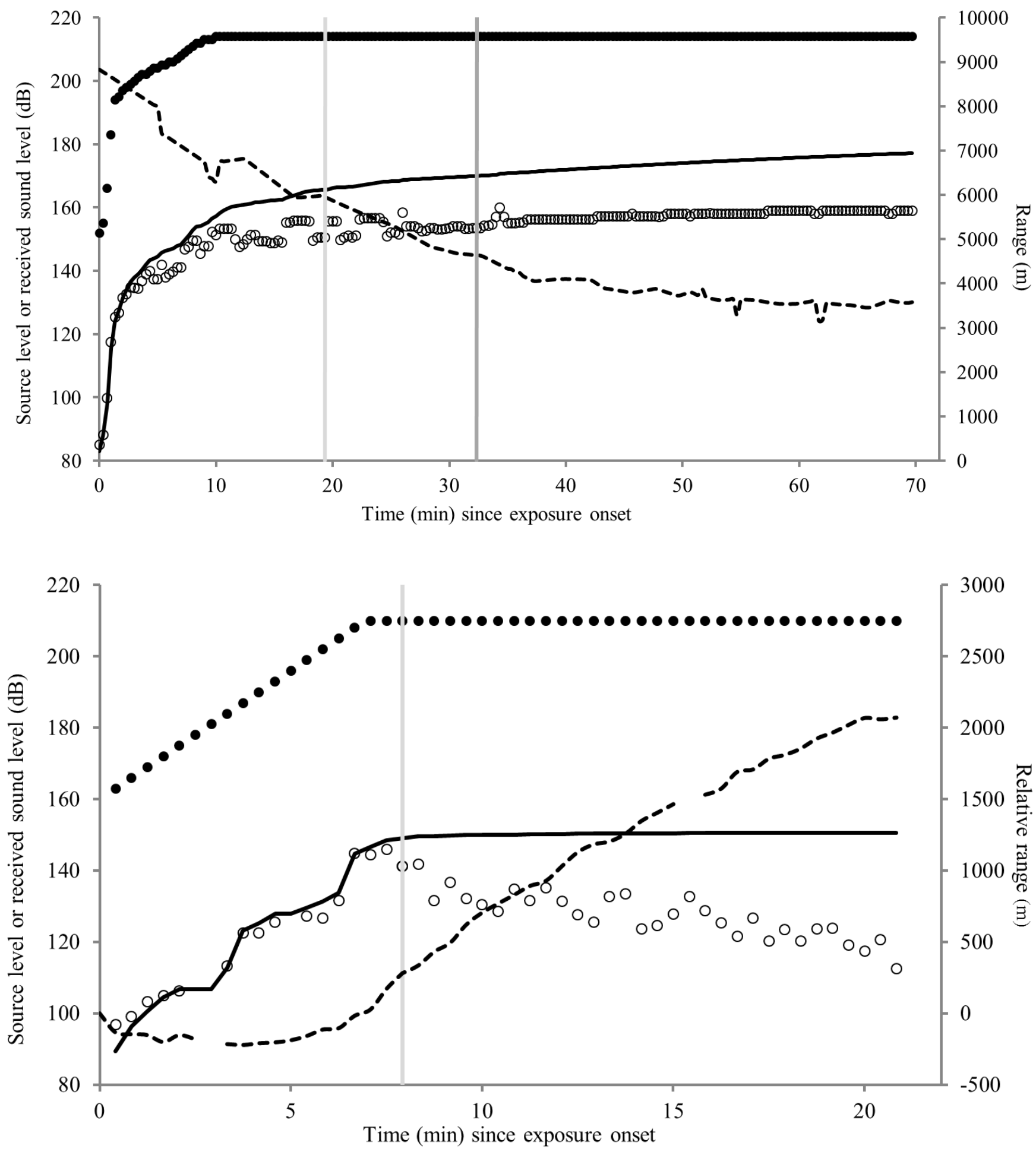

Figure 4. 


\section{Supplementary material}

Table S1. Combined minke whale dataset collected by the 3S-project in Norwegian waters in the northeast Atlantic and by the SOCAL project off California in the central eastern Pacific.

\begin{tabular}{llll}
\hline Tag ID & Tag type & $\begin{array}{l}\text { Duration } \\
(\mathrm{h})\end{array}$ & Description of data \\
\hline ba10_148 & Wildlife Comp MK9 & 3 & 3S-baseline \\
ba11_180 & Star-Oddi TDR & 19 & 3S-CEE $(1.3-2.0 \mathrm{kHz})$ \\
ba13_265 & DTAG & 3 & SOCAL-baseline \\
ba14_211 & DTAG & 6.5 & SOCAL-CEE $(3.5-4.05 \mathrm{kHz})$ \\
\hline
\end{tabular}



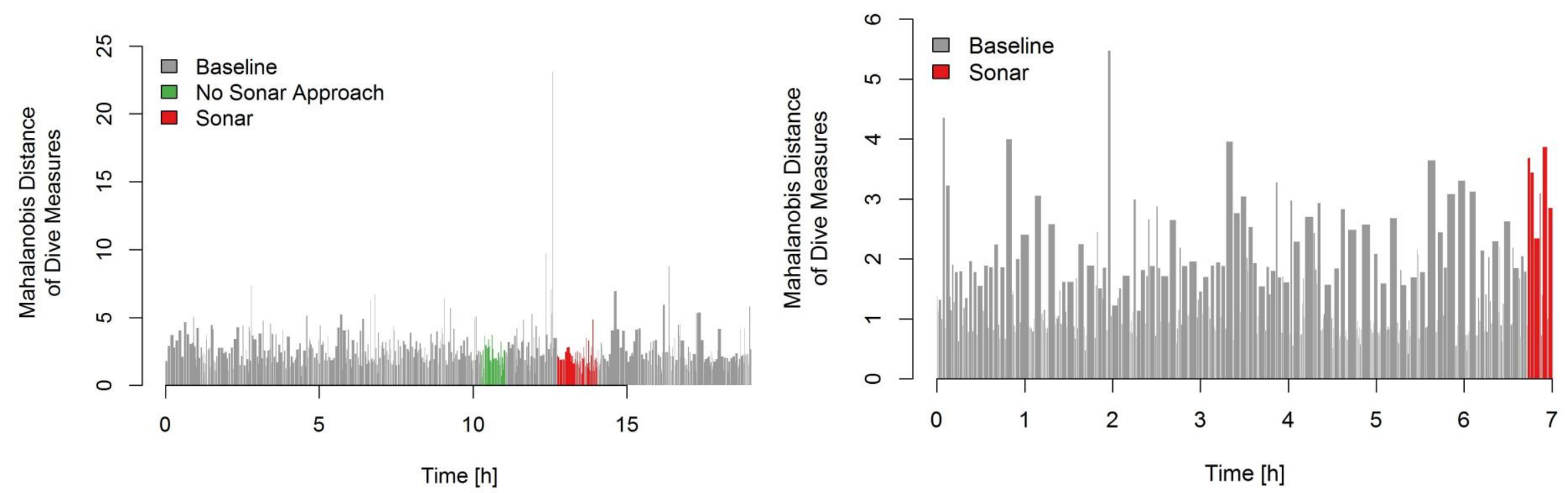

Figure S1: Dive-by-dive Mahalanobis distances as a function of time for the animals exposed to sonar, $3 S$-CEE (left) and SOCAL-CEE (right). Dives during no-sonar control are indicated in green and during sonar exposure in red. 